\title{
Escolher/avaliar materiais didáticos digitais: concepções de professores e implicações em suas práticas docentes ${ }^{1}$
}

Katia Alexandra de Godoi e Silva

Universidade Anhanguera de São Paulo (UNIAN) katia.a.silva@educadores.net.br

\author{
Maria Cristina Lima Paniago \\ Universidade Católica Dom Bosco cristina@ucdb.br
}

Resumo: Este estudo apresenta o recorte de uma pesquisa de estágio pós-doutoral realizada com professores do ensino superior participantes de um grupo de estudo. A fundamentação teórica suscita a questão da escolha e avaliação dos materiais no formato digital. Metodologicamente, o trabalho caracteriza-se como pesquisa de abordagem qualitativa e utiliza a entrevista como instrumento de produção dos dados, no intuito de criar um espaço de interlocução, escuta atenta, reflexão e decisão compartilhada. Os resultados apontam o processo de formação como algo processual, gradativo e que demanda mais discussões sobre a temática dos Materiais Didáticos Digitais, tanto inicial como continuada, priorizando autonomia, autoria e criticidade dos professores em formação.

Palavras-chave: Escolha e Avaliação de Materiais Didáticos Digitais, Formação Continuada de Professores, Contexto Digital.

To choose/to evaluate digital didatic materials: teachers' conceptions and implications in their teaching practices

Abstract: This study presents part of a postdoctoral research carried out with higher education teachers participating in a study group. The theoretical basis raises the question of the choice and evaluation of materials in the digital format. Methodologically, the work is characterized as qualitative research and uses the interview as an instrument of data production, in order to create a space for dialogue, attentive listening, reflection and shared decision. The results point to the process of formation as something procedural, gradual and that demands more discussions on the subject of Digital Didactic Materials, both initial and continued, prioritizing autonomy, authorship and criticality of the teachers in formation.

Keywords: Choice and Evaluation of Digital Didatic Materials, Teachers'Continuous Training, Digital Context.

\section{Contextuatizando a temática - o processo de escolha e avaliação de materiais didáticos digitais}

A escolha e avaliação de Material Didático Digital (MDD), realizadas por professores, constituem-se como um dos múltiplos temas das Tecnologias Digitais de Informação e Comunicação (TDIC) na educação, objeto principal deste artigo. Trata-se de um tema que conta com pesquisa extensa, de mais de 20 anos, com propostas de diversos autores.

No intuito de elucidar a diversidade e complexidade que essa temática suscita, pontuamos alguns pressupostos e concepções que se relacionam e podem auxiliar no contexto da pesquisa: (1) a necessidade de (re)conceituar os termos MDD e os instrumentos de avaliação desses materiais direcionados para professores; (2) o aumento da disponibilidade de MDD; o distanciamento e a desintegração das TDIC; e,

\footnotetext{
${ }^{1}$ Parte deste trabalho foi apresentado e publicado nos anais do evento V Seminário Web-Currículo, Educação e Cultura Digital, PUC-SP, outubro, 2017. Essa versão encontra-se ampliada.
} 
consequentemente, desses MDD do currículo; (3) a formação de professores para o uso da TDIC na educação e, mais especificamente, para a escolha desses materiais no formato digital.

O primeiro pressuposto faz referência à necessidade de (re)conceituar os termos MDD e instrumentos de avaliação desses materiais direcionados para professores.

Para conceituar o termo MDD, corroborando Ramos (2013, p. 87) e adotamos como conceito de MDD, aqueles recursos "[...] potencialmente inovadores no que diz respeito à possibilidade de mudança das práticas educativas dos professores, proporcionando uma oportunidade de acrescentar valor às aprendizagens dos estudantes”.

Com essa definição dos MDD, também é necessário pensar no potencial de uso que desses se faz em contexto pedagógico. Assim, para além da definição dos recursos, o foco precisa estar na potência de uso que se faz do MDD. Almeida (2005), Prado (2003), Almeida e Valente (2011), trazem contribuições teóricas sobre a intencionalidade e a importância da mediação e intervenção pedagógica do professor em contexto de uso desses recursos digitais. Retomando os estudos desses autores, verifica-se que dominar e compreender as potencialidades que os materiais oferecem é essencial para auxiliar o professor nos processos de ensino e aprendizagem. Embora o domínio tecnológico não seja prerrequisito, o não domínio impede o avanço do professor em relação às possibilidades (potencialidades, vantagens e limitações) pedagógicas, além da compreensão de onde, quando, como, porque e para que utilizar determinado material.

Evidencia-se, assim, que a utilização de um MDD, em contexto de uso, embora dependa de fatores tecnológicos, concretiza-se fundamentalmente na ação do professor. É essa ação em contexto, associada com o domínio e a compreensão das potencialidades pedagógicas do MDD, que, segundo Ramos et al. (2011) possibilitará e auxiliará os professores na seleção criteriosa dos materiais. Essa seleção poderá ser feita por meio da sua avaliação (com o uso de instrumentos de avaliação).

A concepção de avaliação de MDD, realizada por professores, vem sendo discutida por diversos autores (CAMPOS, 1994; SQUIRES; PREECE, 1996; GAMEZ, 1998; SQUIRES; PREECE, 1999; SILVA, 2002). Esses autores são proponentes de instrumentos de avaliação. No entanto, esses instrumentos avaliativos estão dentro de uma abordagem prescritiva (classificação final).

No entanto, Shaghnessy (2002), Ramos, Teodoro, Maio, Carvalho e Ferreira (2004) e Godoi e Silva (2013), apontam para a discussão da avaliação de MDD em contexto. A necessidade de considerar o contexto refere-se à escolha e avaliação de MDD na prática pedagógica do professor.

A partir desse panorama geral sobre os conceitos dos MDD e dos instrumentos de avaliação, retomamos o segundo pressuposto, que auxilia no contexto da pesquisa, o qual se refere ao aumento da disponibilidade dos materiais no formato digital, $o$ distanciamento e a desintegração das TDIC e, consequentemente, desses materiais do currículo.

Em relação ao aumento desses materiais, Schlünzen Jr (2009, p. 119) explica que "[...] encontramos atualmente iniciativas governamentais e institucionais que visam oportunizar recursos tecnológicos para o professor utilizar em suas práticas pedagógicas de maneira gratuita, de livre acesso à Web".

De acordo com Piconez e Nakashima (2011, p. 369), esse fato também “[...] está relacionado ao barateamento dos equipamentos, políticas públicas voltadas para a inclusão digital, reestruturação de projetos pedagógicos escolares, prevendo o uso das TDIC, dentre outros". 
Em outros estudos, realizados por Weston e Bain (2010), nos Estados Unidos da América (EUA), o uso das TDIC na escola, em geral, recai sobre a tecnologia, ou seja, o ensino de aplicativos.

Corroborando essas pesquisas, Almeida e Valente (2011), colocam que, grande parte das atividades realizadas, tanto nos laboratórios de informática, como no uso das tecnologias móveis, é voltada ao ensino de aplicativos, além de softwares para acessar a informação (p. ex.: os navegadores). Dessa forma, nenhuma dessas iniciativas está relacionada com alterações do processo de ensinar e aprender (WESTON; BAIN, 2010; ALMEIDA; VALENTE, 2011). "Elas simplesmente automatizam velhas práticas" (ALMEIDA; VALENTE, 2011, P. 72), ou seja, "[...] não exploram o potencial desse tipo de recursos, utilizando "velhas abordagens com novas tecnologias"” (RAMOS, 2013, p. 94).

Esta reflexão torna-se ainda mais pertinente se considerarmos, sobretudo nos últimos anos, o esforço realizado no Brasil, dos programas e projetos governamentais para a implantação e formação das TDIC na educação. Como é exemplo o Programa Nacional de Tecnologia Educacional (ProInfo) ou o Programa Um Computador por Aluno (ProUCA), que estão relacionados tanto à implantação de equipamentos, recursos digitais e conteúdos educacionais, que podem melhorar a infraestrutura das escolas, como em relação à formação de professores para a utilização pedagógica desses recursos. Embora em muitas situações ainda estejam aquém das necessidades e sejam insuficientes para chegar a todos os professores e alunos. No entanto, essas pesquisas e reflexões sobre as políticas públicas reforçam a ideia de que o acesso a essas tecnologias abre portas a uma multiplicidade de conteúdos e, consequentemente, aos MDD.

Ramos (2013, p. 89) adverte que esse aumento da quantidade de conteúdos e recursos digitais, decorrentes da evolução da tecnologia e do seu uso generalizado, coloca importantes desafios tanto à escola, como à formação de professores, principalmente relacionados à apropriação, ou seja, "[...] criando-se e ou aprofundando-se um hiato cada vez maior entre aquilo que os alunos, os professores e as famílias, enquanto cidadãos, podem aceder e usar e aquilo que pode ser explorado em contexto educativo formal, na sala de aula, em especial".

Por isso, faz-se necessário e importante refletir sobre os desafios que nos são impostos, como profissionais e professores, situados nesse contexto de "abundância" de tecnologias, de conteúdos, recursos e MDD.

Ramos, Teodoro e Ferreira (2011), Almeida e Valente (2011) e Ramos (2013) corroboram a ideia de que uma das principais dificuldades enfrentadas, em relação ao uso regular das tecnologias e do MDD, ainda se configura no processo de apropriação das TDIC na prática pedagógica, assim como o desenvolvimento de condições para que os professores possam escolher e avaliar o potencial desses recursos para uso nas suas salas de aulas. Pois acreditam que desenvolver essas capacidades deveria ser uma preocupação central em termos de oportunidades de formação.

Kenski (1998) e Almeida (2002) também alertam que a questão central diz respeito à apropriação das tecnologias, ou seja, como as TDIC têm sido incorporadas aos processos educacionais. Para muito além do acesso ou da disponibilidade de recursos, compete aos professores a apropriação crítica das TDIC aos processos pedagógicos, para que, de acordo com Kenski (1998) e Almeida (2002), possam conhecer suas vantagens e desvantagens, seus riscos e possibilidades, e fazer escolhas conscientes sobre sua utilização e, assim, transformá-las, redimensioná-las e integrá-las, em alguns momentos, e dispensá-las em outros.

Os estudos sobre a apropriação das TDIC, realizados em diferentes contextos (RIEBER; WELLIEVER, 1989; RUSSEL, 1996; SANDHOLTZ; RINGSTAFF; DWYER, 1997; 
BORGES, 2009), indicam que esse processo acontece por estágios e esse processo de mudança de estágio para melhorar a ação pedagógica do professor demanda tempo.

As questões da apropriação estão relacionadas ao terceiro pressuposto: a formação de professores. No Brasil, a preocupação com a formação de professores não é recente. De modo geral, tem sido sempre discutida por diversos autores, como por exemplo Imbernón (2006, 2010). O recorte deste estudo, não reside em analisar os momentos históricos pelos quais passou e/ou tem passado a formação de professores, nem tampouco suas perspectivas. Nosso propósito é apenas refletir sobre como os professores estão sendo orientados nas formações continuadas sobre a questão da escolha e avaliação de MDD.

Godoi e Silva (2013) identifica a ausência de formação numa perspectiva de análise crítica e compreensão sobre as potencialidades educacionais subjacentes aos MDD, nos programas e projetos governamentais no Brasil, para a implantação e formação das TDIC na educação. Na literatura consultada, ocorreu apenas uma formação de professores para a escolha desses materiais, na qual foi desenvolvido um instrumento de avaliação ${ }^{2}$, nos anos de 1992 e 1993, no CIES/Educom da Universidade Federal do Rio de Janeiro (UFRJ).

No intuito de fomentar a discussão sobre a escolha e avaliação de MDD, Godoi e Silva (2013) buscou, no contexto de uma escola pertencente ao Projeto $\mathrm{UCA}^{3}$, viabilizar uma formação de professores reflexiva e contextualizada, por meio da integração e ressignificação de instrumentos de avaliação de MDD direcionados para professores. A partir dessa formação com professores do ensino fundamental, no Estágio Pós-doutoral, verificamos a necessidade de dar início à aproximação dessa temática com os professores do ensino superior, para compreender as reflexões sobre as concepções desses professores/pesquisadores de um grupo de estudo e pesquisa sobre a escolha e avaliação de MDD, assim como as implicações de uma formação sobre essa temática nas suas práticas pedagógicas.

\section{Metodologia - passos trilhados}

Adotamos, para este estudo, a metodologia qualitativa, pois, de acordo com Chizzotti (2006), a pesquisa qualitativa implica a "[...] partilha densa com pessoas, fatos e locais que constituem objetos de pesquisa, para extrair desse convívio os significados visíveis e latentes que somente são perceptíveis a uma atenção sensível" (CHIZZOTTI, 2006, p. 28).

Neste estudo, foram realizados dois encontros, para que os pesquisadores mantivessem uma relação reflexiva. Nessa interação, abrimos um diálogo para que o tema em questão pudesse ser aprofundado. Assim, o primeiro encontro com os pesquisadores resumiu-se à exposição dos objetivos da pesquisa e ao convite para que refletissem sobre o significado das leituras (realizadas no decorrer de um semestre em um grupo de estudos e pesquisa) sobre a escolha e avaliação de MDD. O segundo encontro foi agendado após a transcrição dos dados construídos na primeira entrevista, os quais foram colocados à disposição dos entrevistados, que puderam concordar, discordar ou acrescentar novos dados.

Yunes e Szymanki (2005, p. 4) explicam que, na entrevista reflexiva, o primeiro momento da pesquisa pode propiciar uma estruturação de ideias, o qual pode ser modificado diante da exposição organizada do momento seguinte. "Essa consideração mostra o dinamismo das informações que obtivemos em nossas pesquisas e aponta para o cuidado de não apresentá-las como algo definitivo, mas como possibilidades de transformações".

\footnotetext{
${ }^{2}$ Metodologia de Avaliação da Qualidade do Software Educativo (MAQSE).

${ }^{3}$ Projeto Um Computador por Aluno da Escola Municipal de Educação Infantil (Emef) Governador André Franco Montoro, no Município de Campo Limpo Paulista, SP.
} 
No terceiro e último momento, foram colocadas à disposição dos entrevistados, as interpretações das suas falas à luz das teorias requeridas. Desta forma, os entrevistados puderam comentar e trazer contribuições. Assim, a partir desses encontros, objetivamos compreender as concepções desses pesquisadores sobre a escolha e avaliação de MDD e as implicações dessa temática às práticas pedagógicas desses professores do ensino superior. Vale ressaltar que participaram desse estudo, quatro professores/pesquisadores integrantes de um grupo de pesquisa e estudos: [P1] Graduação em Pedagogia, mestrado em Educação e doutorando em Educação, técnico em assuntos educacionais em uma universidade pública e professor de universidade privada na modalidade EAD. [P2] Graduação em Pedagogia, mestrado e doutorado em Educação, professor e coordenador em uma faculdade privada. [P3] Graduação em Design, mestrado em Comunicação Social e doutorado em Educação, professor em uma universidade pública. [P4] Graduação em História, mestrado em Letras e doutorado em Educação, técnico em assuntos educacionais em uma universidade pública.

A partir dos registros textuais retirados das transcrições das entrevistas reflexivas com esses professores/pesquisadores, iniciamos a análise interpretativa. Para Szymanski (2004, p. 78), esse processo se dá na relação com o texto de referência, ou seja, com os registros textuais das transcrições, a partir dos quais emergem novas articulações conceituais. "Leituras e releituras do texto completo das entrevistas, com anotações às margens, permitem ao longo do tempo a elaboração de sínteses provisórias, de pequenos insights, e a visualização das falas dos participantes, referindo-se aos mesmos assuntos". Esse momento envolve a imersão do pesquisador nos dados e a sua forma particular de agrupar esses mesmos assuntos, segundo a sua compreensão. Szymanski (2004, p. 78), chama esse momento de "explicitação de significados". Após essa explicitação, no decorrer dos registros textuais, optamos por agrupá-los em grandes temas. Esses temas representaram o fio condutor que perpassou várias "explicitações de significados" no decorrer da análise. Vale destacar ainda que consideramos os temas que apontaram para a sua relação com um contexto educacional mais amplo, assim como tornaram possíveis discussões mais aprofundadas, sobre as concepções dos professores/pesquisadores sobre o processo de escolha e avaliação de MDD e as implicações desse processo de escolha de materiais no formato digital em suas práticas pedagógicas.

Por fim, na análise, que se encontra a seguir, foram utilizados trechos dos depoimentos, ou seja, as falas dos professores/pesquisadores para dar suporte às interpretações e que desencadearam as discussões e problematizações para a construção desse estudo.

\section{Análise dos dados - $O$ que os professores/pesquisadores têm a dizer?}

Foi a partir da análise das especificidades das entrevistas que a relação entre os temas emergentes tornou-se evidente, pelo fato de ter enfatizado as concepções e implicações da temática para os pesquisadores. Desta forma, essas temáticas, denominadas e organizadas em seus respectivos objetivos específicos, são apresentadas a seguir.

3.1 As concepções dos professores/pesquisadores sobre o processo de escolha e avaliação de materiais didáticos digitais

A partir da contextualização da temática, evidencia-se uma necessidade cada vez mais premente na atualidade de refletir sobre processos de formação, tanto inicial, como continuada, que preparem os professores para uma análise crítica e reflexiva do material no formato digital, voltada para um processo de escolha e avaliação desses materiais no contexto de utilização.

A partir dessa perspectiva reflexiva, iniciamos as problematizações com os professores/pesquisadores, especificamente, as concepções sobre o processo de escolha e 
avaliação de MDD de professores do ensino superior em processo de formação continuada.

As entrevistas com esses professores/pesquisadores possibilitaram constatar um movimento de construção de significados, os quais foram sendo ressignificados no decorrer do processo de formação.

Esses significados estão articulados nas falas dos professores/pesquisadores e, por isso, optamos por mantê-las na íntegra para facilitar a compreensão da pesquisa. Um professor/pesquisador relatou:

Quando eu tive contato com o material, eu confesso... [...] é como se eu não tivesse muito bem a noção do que era, do que era esse material didático digital e esse processo de avaliação desse material. Então, foi no grupo de estudo que a gente começou e a gente já começou com a leitura dos textos... [...] E aí começou a fazer mais sentido pra mim. [...] E depois, pra minha prática, eu achei muito importante, muito interessante, porque a gente compreende que a gente tem uma infinidade de material pronto, que a gente não sabe muito bem onde está, a gente não sabe muito bem de que forma que está armazenado e nem se ele tem algum rigor, ou se ele é alguma coisa que foi produzida sem nenhum tipo de preocupação, de cuidado para o fim educativo e, às vezes, a gente pega esse material e utiliza sem saber muito bem a fonte. [...] Então, eu acho que tudo isso foram aprendizagens que a gente fez a partir das discussões dos textos no grupo. [P1]

Esse extrato revela que os estudos sobre a escolha de MDD tiveram um significado para a formação continuada da professora/pesquisadora, que relata desconhecer os conceitos pertinentes ao MDD e ao processo de escolha e avaliação desses materiais.

O conceito de MDD está relacionado ao avanço do desenvolvimento das TDIC e, em consequência, ao aumento considerável da disponibilidade, multiplicidade, diversidade e à própria noção de conteúdo educativo que são desenvolvidos para diversas áreas do conhecimento.

Essa ação, em contexto associado com o domínio e a compreensão das potencialidades pedagógicas do MDD, segundo Ramos et al. (2011), auxiliará os professores a escolher de forma criteriosa os materiais. Essa escolha poderá ser feita por meio da sua avaliação em contexto (SHAGHNESSY, 2002; RAMOS et al., 2004). Apesar da complexidade desse tipo de avaliação, essa análise realizada pelo professor permite compreender o que cada material pode oferecer e/ou possibilitar como potencial para o processo de ensino e aprendizagem.

Após constatar a complexidade que envolve o conceito de MDD e compreender como se estabelece o processo de avaliação desses materiais no contexto de sua utilização, a professora/pesquisadora revela que ressignificou sua prática pedagógica, pois começou a ser mais criteriosa na escolha desses materiais.

Outra professora/pesquisadora relata:

Bom, pra mim, inicialmente, por ter sido um assunto que eu não tinha domínio, teve um significado relacionado à minha própria formação. E como professora do curso de Pedagogia, os estudos possibilitaram reconhecer a importância de discutir com os acadêmicos oportunamente critérios para avaliação de material didático digital. [...] Outro aspecto diz respeito ao encaminhamento dos textos organizados e discutidos durante o estudo, pois com as leituras pude me aproximar mais do que se tratava a questão da avaliação dos materiais didáticos digitais. E é fundamental! Porque estamos acostumados a discutir critérios de avaliação de materiais didáticos de modo geral, mas não na perspectiva somente da avaliação de materiais didáticos digitais, mais do que isso, é preciso analisar, utilizar, criar condições para utilização dos materiais. Entendo que foi de fundamental importância, para minha formação. [P2]

Esse extrato retrata que os estudos sobre a escolha e avaliação de MDD tiveram um significado para a formação continuada da própria professora/pesquisadora, no sentido de que era uma temática fora de seu domínio e que, a partir da aproximação e apropriação dessa temática, conseguiu compreender a sua relevância. 
A pesquisadora também ponderou sobre a ocorrência de discussões, no âmbito das políticas públicas, de iniciativas que tratam da avaliação de livros, com o objetivo de subsidiar o trabalho pedagógico dos professores e, ao mesmo tempo, a ausência de discussões na perspectiva do MDD. Mais do que a ausência, a pesquisadora considera importante trazer à baila essa reflexão no âmbito da formação inicial de professores, a partir do uso pedagógico que dele se faz. Levar a reflexão do processo de escolha e avaliação de MDD para o âmbito da formação inicial de professores é fundamental, tendo em vista que formar professores para o uso das tecnologias ainda é um desafio (BONILLA, 2011).

Desta forma, a partir do desejo de levar essa discussão para o âmbito da formação inicial, o relato revela, ainda, que a pesquisadora atribui outro significado à sua prática pedagógica. Em outras palavras, ela a (re)construiu, na medida em que pretende discutir e problematizar essa temática com seus alunos de um curso de licenciatura em Pedagogia.

3.2 As implicações do processo de escolha e avaliação de materiais didáticos digitais na prática pedagógica dos professores/pesquisadores

Para compreender as implicações dessa formação nas práticas dos professores/pesquisadores, a seguir apresentamos trechos das entrevistas:

Olha... Como eu também sou professor do ensino superior e trabalho com as mídias digitais, as novas mídias, no processo de formação de professores, em Artes Visuais, eu vejo assim, o meu foco, a minha compreensão, a partir desses textos, se ampliaram muito, o que eu já fazia empiricamente, ou por intuição, agora eu consigo um conceito mais acadêmico e mais pedagógico. Desde que eu entrei no Doutorado, eu dizia, eu tenho muito domínio sobre a questão do design, da tecnologia, uma parte pedagógica, mas eu preciso de mais nesse aspecto. Então eu vejo como um avanço na minha forma de interpretar, aquilo que eu vou levar, quando eu voltar para a sala de aula. [P3]

\begin{abstract}
Essa formação faz... ela é um tijolo na construção maior. Por exemplo, a notícia que eu tenho agora, eu estou muito animado com isso, é que eu retornando à Universidade, eu estava afastado [...], eu vou trabalhar com materiais educacionais. Então, quer dizer, o impacto, se essa palavra é adequada... a implicação desses estudos e de outros ainda que lida com os materiais educacionais, [...] eu não tenho a menor dúvida [...] eu penso que é uma referência importante. O impacto vai ser significativo! [P4]
\end{abstract}

De modo geral, esses extratos revelam que as implicações da formação, na vida pessoal e profissional desses professores/pesquisadores, possibilitaram reflexões que estão relacionadas ao processo contextual da escolha e avaliação de MDD e, consequentemente, à ressignificação de suas práticas pedagógicas.

A partir da análise dos extratos, é possível observar que, após os professores/pesquisadores constatarem a complexidade que envolve a temática e à medida que começam a apropriar-se dela, iniciam uma reflexão de forma mais crítica sobre os materiais no formato digital, e também sobre a importância de pensar essa escolha de forma contextual.

Estudos sobre apropriação indicam que esse processo não é simples, requer tempo e acontece em fases (SANDHOLTZ; RINGSTAFF; DWYER, 1997; BORGES, 2009).

Gradativamente, nos relatos dos professores/pesquisadores há indícios de um movimento de apropriação e ressignificação de suas atitudes e práticas pedagógicas. A ressignificação da prática pedagógica implica dar "vida" à teoria discutida nesse processo de formação continuada sobre a escolha e avaliação de MDD e integrar esses conceitos às práticas pedagógicas. Desta forma, gradativamente, os professores/pesquisadores vão ressignificando suas práticas pedagógicas, adequando as escolhas desses materiais de acordo com as necessidades dos contextos. 
Nesse estudo, compreendemos o conceito de 'contexto' conforme desenvolvido por Figueiredo e Afonso (2006), os quais adotaram um modelo que postula três definições: evento de aprendizagem, refere-se a uma situação onde um indivíduo aprende; conteúdo, que é a informação que foi estruturada e codificada como texto; contexto propriamente dito, que trata do conjunto de circunstâncias relevantes para o aprendiz construir seu conhecimento.

Nesse modelo, a concepção de contexto é dinâmica e percebida somente por meio de suas interações com o aprendiz, sendo que essas interações organizam o contexto. Nessa perspectiva, um gera o outro e um não pode existir sem o outro.

Assim, as interações percebidas durante o processo de formação e, consequentemente, durante a ressignificação da prática pedagógica desses professores, a partir do processo de escolha e avaliação de MDD, acontecem num contexto dinâmico e contínuo.

Nesse sentido, a síntese dos resultados alcançados neste tópico, sobre o que os professores/pesquisadores têm a dizer, revelou o potencial em termos de redimensionar as concepções e implicações sobre o processo de formação para a escolha e avaliação de MDD pelos professores/pesquisadores. Tal redimensionamento acontece por meio das interações em contexto, num movimento contínuo de possibilidades de ressignificações das práticas pedagógicas desses professores/pesquisadores.

\section{Considerações finais e perspectivas}

O presente estudo desenvolveu-se com o propósito de analisar a formação continuada dos professores/pesquisadores de um grupo de estudo e pesquisa sobre o processo de escolha e avaliação de MDD, buscando analisar especificamente as concepções dos professores/pesquisadores sobre o processo de escolha e avaliação de MDD, assim como, as implicações do processo de escolha e avaliação desses materiais na prática pedagógica desses professores/pesquisadores.

A partir dos resultados apresentados, aprendemos que todo esse processo acontece gradativamente e observamos que ainda há grandes desafios. Desafios principalmente relacionados à discussão dessa temática, no âmbito da formação de professores, tanto inicial, como continuada.

Portanto, acreditamos que a escolha e avaliação desses materiais é um 'eixo central' do processo de formação dos professores. E, vislumbramos que essa formação possa garantir, ao lado dos saberes científico e pedagógico, a capacidade de autonomia, autoria e criticidade desses professores.

\section{Referências}

ALMEIDA, M. E. B. Educação, projetos, tecnologia e conhecimento. 2. ed. São Paulo: Proem, 2005.

; VALENTE, J. A. Tecnologias e currículo: trajetórias convergentes ou divergentes? São Paulo: Paulus, 2011.

BONILLA, M. H. S. Formação de professores em tempos de web 2.0. In: FREITAS, M. T. A. (Org.). Escolas, tecnologias digitais e cinema. Juiz de fora: Editora UFJF, 2011.

BORGES, M. A. F. Apropriação das tecnologias de informação e comunicação pelos gestores educacionais. 2009. 321 f. Tese (Doutorado)-Programa de Pósgraduação em Educação: Currículo, Pontifícia Universidade Católica de São Paulo (PUC-SP), São Paulo, 2009. 
CAMPOS, G. H. B. Metodologia para avaliação da qualidade de software educacional. Diretrizes para desenvolvedores e usuários. 1994. 232 f. Tese (Doutorado) - Programa de Pós-graduação em Engenharia de Produção, Universidade Federal do Rio de Janeiro, Rio de Janeiro/RJ, 1994.

CHIZZOTTI, A. Pesquisa qualitativa em ciências humanas e sociais. Petrópolis/RJ: Vozes, 2006.

FIGUEIREDO, A. D.; AFONSO, A. P. Context and learning: a philosophical framework. In: FIGUEIREDO, A. D.; AFONSO, A. P. (Org.). Managing Learning in Virtual Settings: The Role of Context. Hershey, PA: Idea Group Publishing, PLC, 2006.

GODOI e SILVA, K. A. Avaliação de material didático digital na formação continuada de professores do ensino fundamental: uma pesquisa baseada em design. Tese de Doutorado, Programa de Pós-Graduação em Educação: Currículo, Pontifícia Universidade Católica de São Paulo, São Paulo, 2013.

IMBERNÓN, F. Formação docente e profissional: formar-se para a mudança e incerteza. 6. ed. São Paulo: Cortez, 2006.

IMBERNÓN, F. Formação continuada de professores. Porto Alegre: Artmed, 2010.

KENSKI, Vani Novas tecnologias: o redimensionamento do espaço e do tempo e os impactos no trabalho docente. Revista Brasileira de Educação, n. 8, p. 58-71, Brasília, mai/ago., 1998.

PRADO, M. E. B. B. Educação a distância e formação do professor: redimensionando concepções de aprendizagem. 2003. 279 f. Tese (Doutorado) Programa de Pós-graduação em Educação: Currículo, Pontifícia Universidade Católica de São Paulo (PUC-SP), São Paulo, 2003.

PICONEZ, S. C. B.; NAKASHIMA, R. H. R. Equipes de produção de materiais digitais de aprendizagem e os critérios de usabilidade técnica e pedagógica: um diálogo necessário. In: BARROS, D. M. V.; NEVES, C.; SEABRA, F. B.; MOREIRA, J. A. M.; HENRIQUES, S. (Orgs.). Educação e tecnologias: reflexão, inovação e práticas. Lisboa/Portugal: Publicação Digital Gratuita, 2011.

RAMOS, J. L. Recursos educativos digitais potencialmente inovadores ou oportunidades de acrescentar valor à aprendizagem. In: ALMEIDA, M. E. B.; DIAS, P.; SILVA, B. D. (Orgs.) Cenários de inovação para a educação na sociedade digital. São Paulo: Edições Loyola, 2013. pp. 87-122.

; TEODORO, V. D.; MAIO, V. M.; CARVALHO, J. M.; FERREIRA, F. M.

Sistema de avaliação, certificação e apoio à utilização de software para a educação e formação. Cadernos Sacausef, Portugal, n. 1, p. 21-44, 2004. Disponível em: $<$ http://www.crie.minedu.pt/files/@crie/1186584566_Cadernos_SACAUSEF_22_45.pdf>. Acesso em: 5 mar. 2012. 
; TEODORO, V. D.; FERREIRA, F.M. Recursos educativos digitais: reflexões sobre a prática. Cadernos Sacausef, Portugal, n. 7, p. 11-35, 2011. Disponível em: $<$ http://www.crie.minedu.pt/files/@crie/1330429397_Sacausef7_11_35_RED_reflexoes_pratica.pdf > Acesso em: 20 jul. 2017.

RIEBER, L. P.; WELLIVER, P. W. Infusing educational technology into mainstream educational computing. International Journal of Instructional Media. v. 1, n. 16, 1989 , p. 21-32.

RUSSEL, A. L. Six stages in learning new technology. AMERICAN EDUCATIONAL COMMUNICATIONS AND TECHNOLOGY ASSOCIATION CONVENTION, 18., 1996, Indianapolis. Anais eletrônicos... Indianapolis: Iowa State University, 1996. Disponível em: <http://www.russellsynergies.com.au/pdf/RussellSixStages96.pdf> . Acesso em: 20 jun. 2013.

SCHLÜZEN JR, K. As tecnologias de informação e comunicação na formação inicial do professor: um desafio a ser superado. In: PINHO, S. Z. (Org.). Formação de educadores: o papel do educador e sua formação. São Paulo: Unesp, 2009.

SHAUGHNESSY, M. R. Educational Software Evaluation: A contextual approach. Ohio, 2002, $269 \mathrm{f}$. Thesis (Doctorate of Philosophy) - Department of Germanic Languages and Literatures, McMicken College of Arts and Sciences, University of Cincinnati, Ohio, 2002.

SILVA, C. R. O. Maep: Um método ergopedagógico interativo de avaliação para produtos educacionais informatizados. 2002. $224 \mathrm{f}$. Tese (Doutorado) - Programa de Pós-graduação em Engenharia de Produção, Universidade Federal de Santa Catarina, Florianópolis/SC, 2002.

SANDHOLTZ, J. H.; RINGSTAFF, C.; DWYER, D. C. Ensinando com tecnologia: criando salas de aula centradas nos alunos. Porto Alegre/RS: Artes Médicas, 1997.

SQUIRES, D.; PREECE, J. Usability and learning: evaluating the potential of educational software. Computer and Education, v. 27, n. 1, p. 15-22, 1996.

Predicting quality in educational software: evaluating for learning, usability and synergy between them. Interacting with Computers, v. 11, n. 5, p. 467-483, maio 1999.

SZYMANSKI, H. (Org.). A entrevista na educação: a prática reflexiva. Brasília/DF: Liber Livro Editora, 2004.

WESTON, M. E.; BAIN, A. The end of techno-critique: the naked truth about 1:1 laptop initiatives and educational change. Journal of Technology, Learning, and Assessment, v. 9, n. 6, 2010. 